\title{
Uso de kéfir en preparaciones de cocina fría
}

\section{Use of kefir in cold cooking preparations}

\author{
Blanca Azalia López Hernández ${ }^{a}$
}

\begin{abstract}
:
Kefir is a dairy drink produced through the fermentative activity of the microbiota of the granules of the same name on the chemical components of milk whose composition is irregular, semi-hard and yellowish-white in color; it has pre and probiotic properties, low cholesterol, bioavailability of milk components with biological activity and the presence of metabolites, placing it as a functional food, that is, it not only has a nutritional contribution but also benefits one or more physiological functions of the organism, benefiting to the state of health. 1
\end{abstract}

\section{Keywords:}

Kefir, probiotic, prebiotic, functionalfood

\section{Resumen:}

El kéfir es una bebida láctea producida a través de la actividad fermentativa del microbiota de los gránulos del mismo nombre sobre los componentes químicos de la leche1, cuya composición es irregular, semidura y de color blanco-amarillento; posee propiedades pre y probióticas, colesterol bajo, biodisponibilidad de componentes de la leche con actividad biológica y presencia de metabolitos, situándolo como un alimento funcional, es decir que no solo tiene un aporte nutricional sino que beneficia a una o más funciones fisiológicas del organismo beneficiando al estado de salud. 1

\section{Palabras Clave:}

Kéfir, probióticos, prebióticos, alimento funcional

\section{Introducción}

El kéfir es una bebida láctea fermentada cuyo origen se atribuye a las regiones de los Balcanes, Europa del Este y el Cáucaso, su ingesta ha estado presente a lo largo de la historia, pero en los últimos años se ha popularizado debido a los aportes benéficos para la salud que se le atribuyen.

El kéfir es un promotor de la buena salud debido a la presencia de péptidos bioactivos que contribuyen a la regulación y fortalecimiento del sistema inmune ante peligros externos y desequilibrios internos, presentan de igual manera actividad antihipertensiva, antitumoral y antimicrobiana atacando principalmente a la salmonella y escherichia coli.

La presencia de pre y probióticos refuerzan la salud digestiva y el equilibrio del microbiota intestinal, contribuye a regenerar la flora bacteriana, a combatir alergias, asma, enfermedades como colitis, intestino irritable, de Crohn y cutáneas. 2 
Aunque originalmente la producción de kéfir se realizaba con leche de cabra o vaca, actualmente se pueden encontrar a base leches vegetales de coco, de arroz, soya o bien, agua adicionada con algún tipo de azúcar, adquiriendo los carbohidratos, grasas, proteínas, minerales y vitaminas de acuerdo al ingrediente base y gracias a la doble fermentación acido láctica y alcohólica que presentan.

Desarrollo de la práctica:

1. Objetivo general de la práctica:

Realizar preparaciones culinarias frías utilizando como base el kéfir para potencializar su uso en la gastronomía.

2. Instrumentos necesarios:

Licuadora, tabla, cuchillo chef, tazón, vaso old fashion, tabla de madera, miserable, salsera.

3. Insumos requeridos:

\begin{tabular}{|c|c|}
\hline INGREDIENTES & CANTIDAD \\
\hline Smoothie de frutos rojos & \\
\hline Kefír líquido & $0.200 \mathrm{lt}$ \\
\hline Blueberries & $0.050 \mathrm{~kg}$ \\
\hline Fresas & $0.100 \mathrm{~kg}$ \\
\hline Dip de albahaca & \\
\hline Kefír & $0.200 \mathrm{lt}$ \\
\hline Albahaca & $0.020 \mathrm{~kg}$ \\
\hline Pimienta negra molida & $0.001 \mathrm{~kg}$ \\
\hline Sal del Himalaya & $0.001 \mathrm{~kg}$ \\
\hline Tomate deshidratado & $0.030 \mathrm{~kg}$ \\
\hline Kefir seco untable & \\
\hline Kefír sólido & $0.150 \mathrm{~kg}$ \\
\hline Nuez & $0.050 \mathrm{~kg}$ \\
\hline Arándanos & $0.050 \mathrm{~kg}$ \\
\hline \multicolumn{2}{|c}{}
\end{tabular}

Tabla 1. Elaboración propia

Preparación:

Smoothie de frutos rojos

1. Lavar frutos rojos

2. Batir las fresas, la mitad de blueberries y el kefír en la licuadora.

3. Servir en el vaso old fashion

4. Acompañar con blueberries

Dip de albahaca

1. Cortar en chiffonade la albahaca
2. Cortar el tomate deshidratado en trozos pequeños

3. Mezclar la albahaca con el kefír y el tomate, sazonar con sal y pimienta recién molida

Kefír seco untable

1. Trocear las nueces

2. Cortar los arándanos

3. Mezclar las nueces y arándanos con el kefír seco

4. Moldear y servir en la tabla de madera

\section{Conclusiones}

Se concluye que el kefír puede ser utilizado en diversas preparaciones sin necesidad de modificar sus cualidades nutrimentales y aportando características organolépticas agradables a las diferentes recetas culinarias.

\section{Referencias}

[1]. Rodríguez, J., Noriega, J., Lucero, A. \& Tejeda, A. (2017). Avances en el estudio de la bioactividad multifuncionaldelkéfir. Interciencia, No 6(42), pp. 347-354. Recuperado de: https://www.redalyc.org/pdf/339/33951621003.pdf

[2]. Coriat, J., Azuero, A., Gil, S., Rueda, M., Castañeda, C. \& Rosselli, D. (2017). Uso de probióticos en el síndrome de intestino irritable y enfermedad inflamatoria intestinal: una revisión de la literatura. Revista Colombiana Gastroenterología,pp. 141-149. Recupera do de: http://www.scielo.org.co/pdf/rcg/v32n2/0120-9957-rcg-32-02-00141.pdf 